\title{
AN OVERVIEW OF DEVELOPMENTS IN WASTEWATER MANAGEMENT AND THEIR APPLICABILITY IN URBAN INDIA
}

\author{
Saiesha Gupta \\ Benenden School \\ DOI: 10.46609/IJSSER.2020.v05i01.009 URL: https://doi.org/10.46609/IJSSER.2020.v05i01.009
}

\begin{abstract}
The population of India has increased an alarming rate over the past few decades which has created immense pressure on the water resources. Urbanization has simultaneously increased the need for the development of sewage treatment facilities. This paper has explored the importance of Wastewater Management in solving the crisis of water shortages and untreated sewage in urban India. Sewage Treatment in India is inadequate not only because of the lack of treatment facilities but also because of the inefficiency in the operations of existing plants. Centralized treatment of sewage is associated with higher costs and higher risks of environmental degradation and contamination. This paper has explored the scope of the development of decentralized water treatment facilities. Despite the presence of legal provisions against pollution and environmental degradation, water pollution through domestic and industrial waste continues to be a common occurrence in India, which has increased the demand for freshwater and has been responsible for outbreaks of water-borne diseases. It has been found that the effective implementation of legal provisions through the development of wastewater treatment facilities is imperative to solve barriers to sustainable development in India.
\end{abstract}

Keywords: Wastewater, Management, Population, Sewage, Environment

\section{INTRODUCTION}

Wastewater Management is defined as the process through which contaminants are removed from sewage or wastewater, which is then converted into an effluent that can be directly reused, or redistributed within the water cycle with almost no impact on the environment. Wastewater Management primarily occurs in a Water Resource Recovery Factory or a Sewage Treatment Plant which is enabled with the technology necessary to remove pollutants from municipal wastewater (Metcalf \& Eddy, 2003). The supply of clean water is an essential requirement for the establishment and maintenance of diverse human activities. Water resources provide valuable food through aquatic life and irrigation for agriculture production. However, liquid and solid 


\section{International Journal of Social Science and Economic Research}

ISSN: $2455-8834$

Volume: 05, Issue: 01 "January 2020"

wastes produced by human settlements and industrial activities pollute most of the water sources throughout the world (Dhote, et. al., 2012). To fulfill the need for water for a growing global population, it is imperative to not only ensure water conservation but to also treat the significant levels of wastewater that is produced as a result of human activity.

India's population, in particular, is deeply vulnerable to changes in the water supply. The effect of climate change on monsoons has led to the scarcity of water supply. This has hampered development and has specifically crippled agricultural output, a sector on which $60 \%$ of the Indian population relies for livelihood. India is a developing country characterized by rapid rates of urbanization. There has been an increase, from 25.8 million in 1901 to about 387 million in 2011, in urban population of India (Kamyotra \& Bharadwaj, 2011). Combined with the lack of infrastructure, the creation of dense urban pockets has rendered them more susceptible to acute water shortage and sewage overload. Some of the biggest cities in India including New Delhi and Chennai have faced water shortages in 2019 (Sugam, et. al., 2017). Currently, the demand for water in areas that face shortages is fulfilled by transporting water from areas often located hundreds of kilometers. Not only is this economically inefficient, but the energy that the process consumes also has a detrimental impact on the environment. Due to increasing rates of urbanization, the pressure on water resources is expected to increase in the next few years (Kamyotra \& Bharadwaj, 2011). Traditional solutions implemented by the government have failed to address issues related to the shortage of water in the long run. Urbanization has also led to problems associated with the treatment of sewage in cities. The inadequacy of sewage facilities has also contributed to higher rates of environmental degradation and water pollution. It is also considered to be a risk factor for water-borne diseases such as typhoid fever (Mogasale, et. al., 2018).

The impact of shortages of water and lack of sewage treatment has been unequal in different communities in Urban India. Water supply, sanitation measures, and management of sewage and solid wastes is restricted to select parts of cities. The benefits of public infrastructure are accessed by only a fraction of the total urban population. There exist a clear inequity and disparity between the public services received by the inhabitants, depending on their socioeconomic backgrounds and occupations (Kamyotra \& Bharadwaj, 2011). The economic development of India has been accompanied by the widening of economic inequalities between citizens, which is reflected in the lifestyles they lead in urban India. Moreover, the gentrification of housing based on caste and religious lines is common. The water crisis of India specifically hinders the economic development of certain communities, some of which have been historically marginalized. The failure of traditional methods in fulfilling the need for water of India's growing urban population has necessitated the formulation and implementation of alternative methods of water supply. Wastewater management at the grassroots level is considered to be key 


\section{International Journal of Social Science and Economic Research}

ISSN: $2455-8834$

Volume: 05, Issue: 01 "January 2020"

to solving problems associated with water security and environmental degradation in Urban India (Sugam, et. al., 2017). Decentralized wastewater systems are used to treat, dispose or reuse wastewater from small communities, and dwellings. Treatment usually occurs through systems located in the vicinity of these communities. Decentralized systems not only improve public health but also reduce the impact of polluted water on the environment (Sasse, 1998).

\section{BACKGROUND}

The global population boom has rendered water to be one of the scarcest resources in the $21 \mathrm{st}$ century. Moreover, half the world's population resides in concentrated urban regions. Since the industrial revolution, the disposal of waste into water bodies and the pollution of water resources caused by it has led to water shortages. Central to the process of urbanization is the problems associated with providing municipal services and water sector infrastructure, including the provision of both freshwater resources and sanitation services. This has led to widespread public health problems, restricted economic and agricultural output and the destruction of a wide range of ecosystems (Dhote, et. al., 2012). The provision of services essential to solving these problems continues to be a major challenge for policymakers in the developing world. Although India occupies only .4\% of the world's land area, it supports over $15 \%$ of the world's population. Moreover, total annual utilizable water resources of the country only account for $4 \%$ of the global water resources (Kumar, et. al., 2005). This has led to a progressive decrease in the per capita availability of water in India.

Although the collection of wastewater dates back to ancient times, its treatment is a relatively recent development (Chow, et. al., 1972). Modern knowledge of the need for sanitation and treatment of wastewater started in 1855, with a cholera outbreak in London that was proven to be caused by the contamination of the water of the River Thames due to uncontrolled sewage disposal (Cooper, 2001). The degrees of wastewater treatment varies in most developing countries. Domestic wastewater is usually treated in centralized plants, pit latrines, and septic systems but is often disposed of in unmanaged lagoons or waterways, through open or closed sewers. Even though laws mandate large scale industrial facilities to develop comprehensive inplant treatment of wastewater, polluted material is usually discharged directly into water bodies without adequate treatment (Doorn, et. al., 2006). Research has found that only $15 \%$ of collected wastewater passes through treatment plants in Latin America. The treatment of wastewater is considered to be a bigger challenge in countries with high populations. Despite being an industrialized nation that has enjoyed high rates of economic development in the recent past, only $55 \%$ of wastewater is treated in China. Wastewater treatment is absent in most of subSaharan Africa and the Middle East (Dhote, et. al., 2012). Studies conducted by the Central Pollution Control Board (CPCB) of India depict that the existing water treatment capacity is just 


\section{International Journal of Social Science and Economic Research}

ISSN: $2455-8834$

Volume: 05, Issue: 01 "January 2020"

21 percent of the present sewage generation. Untreated sewage is considered to be the main cause of pollution of rivers and lakes (Kamyotra \& Bharadwaj, 2011).

Scientific and technological innovation has led to the development of comprehensive techniques for wastewater management including Fluidized Bed Reactors, Oxidation Ponds and Aerated Lagoons. These are often used by developed countries to treat both domestic and industrial wastewater (Dhote, et. al., 2012). Research conducted by the Industrial Development and Finance Corporation of India has suggested that the inclusion of these systems could be instrumental in solving water shortages faced by cities in Urban India. Moreover, many of these systems also rely on organic processes such as the use of Duckweed and Karnal Technology which makes them cost-efficient and sustainable (Kamyotra \& Bharadwaj, 2011).

\section{DISCUSSION}

It is estimated that about 38,254 million liters per day of wastewater are generated in urban centers comprising Class I cities and Class II towns in India. These cities account for more than $70 \% \mathrm{t}$ of the total urban population of India. The municipal wastewater treatment capacity developed so 300 India Infrastructure Report 2011 far is about 11,787 million liters per day, which amounts to only $31 \%$ of the wastewater generated by these cities. The anticipated freshwater demand is expected to exceed 1,20,000 million liters per day by 2051 (Bharadwaj, 2005). Due to the improvement in infrastructural and sanitation facilities in rural India is expected to increase the wastewater generation in those regions as well. However, wastewater management plans do not address this increasing pace of wastewater generation. Reports by the Central Pollution Control Board suggest that only $21 \%$ of the wastewater produced in India is adequately treated whilst the remaining untreated sewage is disposed of into rivers and lakes (Ahmed, et. al., 2011). The operational capacity of Sewage Treatment Plants of India is underutilized. There is a need to plan strategies and give thrust to policies that give equal weight to augmentation of supplied water as well as the development of wastewater treatment facilities, recycling, recovery, recharging, and storage. The future of urban water supply depends mainly on the efficiency of wastewater treatment systems.

Conventionally, sewage in India is collected through a vast network of sewerage systems and transported to a centralized treatment plant. This process is resource-intensive and economically unsustainable in a developing country like India, which faces multiple challenges in developing public infrastructure. Wastewater Treatment Plants are designed to receive waste from domestic, commercial, and industrial sources and remove materials that degrade water quality and compromise public health and safety when discharged into water receiving systems. The principal objective of wastewater treatment is generally to allow human and industrial effluents 


\section{International Journal of Social Science and Economic Research}

ISSN: $2455-8834$

Volume: 05, Issue: 01 "January 2020"

to be disposed of without danger to human health and to satisfy the increasing demand for water by introducing alternative sources of supply (Mara, 2009). Conventional wastewater treatment consists of a combination of physical, chemical, and biological processes and operations to remove solids, organic matter, and sometimes, nutrients from wastewater. Water passes through three stages of treatment before it is deemed suitable for usage. The preliminary treatment removes coarse solids and other large materials found in raw wastewater, which enhances the impact of subsequent treatment units. Secondary treatment aims to remove residual organics, suspended solids, and colloidal organic matter using aerobic biological treatment processes. A combination of multiple processes which include but are not limited to Trickling Filters, Rotating Biological Contactors and Waste Stabilization ponds are used to treat wastewater, depending on its source. Wastewater sometimes also goes through a round of advanced treatment which aims to eliminate wastewater constituents such as nitrogen, phosphorus, additional suspended solids, refractory organics, heavy metals, and dissolved solids which cannot be removed by secondary treatment. However, many developing countries have been unable to implement comprehensive wastewater treatment programs due to the lack of economic capital. This creates the need for near term risk management and interim solutions prevent adverse impacts from wastewater disposal (Blumenthal, et. al., 2000).

The government of India enacted the Water (Prevention and Control of Pollution) Act in 1974 with the primary objective of preventing and controlling water pollution and restoring water quality to fulfill the increasing demand for freshwater. The Central and State Pollution Control Boards were established for its implementation. The Water Act empowers these boards to lay down and maintain water standards and impose penalties on individual polluters that do not achieve this standard. The Environment Protection Act, 1986, which is an umbrella act providing for the protection and improvement of the environment also authorizes the central government to intervene in cases where standards related to the treatment of hazardous wastes and chemicals, hazardous microorganisms, and transportation of toxic chemicals are violated (Mara, 2009). These standards are industry and community-specific and have been developed by government bodies after comprehensive research. Despite the development of centralized legislation and standards, they are rarely implemented on the ground. Studies have determined that the discharge of untreated sewage is the single most important source of pollution of surface and groundwater in India which is reflective of the large gap that exists between the generation and treatment of domestic wastewater in India. The problem does not only lie in the absence of sufficient treatment capacity but also the inefficiency in operations of existing Sewage Treatment Plants. The state machinery of India has failed to implement these standards and regulations due to corruption and bribery, the vested interests of politicians in businesses that are major polluters and inefficiency and ignorance partly due to the lack of pressure from the public. 


\section{International Journal of Social Science and Economic Research}

ISSN: $2455-8834$

Volume: 05, Issue: 01 "January 2020"

\section{CONCLUSION}

The increasing demand for freshwater and sewage disposal in urban India has presented a major challenge to policymakers. The failure of traditional methods of conservation and recycling has partly failed, which has given rise to the need for efficient wastewater management. Instead of transporting wastewater through long distances for centralized treatment, the Central Pollution Control Board has promoted decentralized treatment at the local level using technology based on natural processes. The treatment in these facilities allows treated wastewater to be used in pisciculture, irrigation, forestry, and horticulture. The residue or sludge is often used as manure and for energy recovery. The remaining nutrients and organics from wastewater enters the natural system of recycling and is used by plants and microbes in the soil. Municipal wastewater can also be recycled for usage in industry/thermal power stations as utility water in cooling towers and boilers (Grover, 2011). It is important to treat water adequately before using it as a productive resource. The absence of adequate treatment can result in health hazards and epidemics.

Land Treatment is an innovative technique for wastewater management. It includes a controlled application of pre-treated wastewater on the land surface to achieve a designated degree of treatment through natural bio-geochemical process wastewater reuse. This increases the productivity of soil which in turn has a positive impact on the economic returns generated through agriculture. It also enhances groundwater levels which have dropped to alarming rates in India. Advanced sewage treatment technologies such as the Membrane Bioreactor (MBR) can treat wastewater at a tenth of the cost of traditional methods. The development and implementation of such techniques in developing countries can be instruments. The combination of improved policies, institutional dialogue, and financial mechanisms imperative to achieve these goals (Mara, 2009). Effluent standards combined with incentives or enforcement can motivate improvements in water management by households and industrial sectors that discharge wastewater from point sources. Strengthening institutional capacity and establishing links between water delivery and sanitation sectors through inter-institutional coordination leads to enhanced efficiency in the management of wastewater and risk reduction (Blumenthal, et. al., 2000).

Even though there have been alarming water supply shortages in India in the recent past, the productive use of wastewater has gradually. This is primarily due to the demand for wastewater treatment facilities by small scale farmers in India, who do not have access to other forms of irrigation. Supported by recent legislative, administrative, and judicial initiatives, environmental regulations in India have also become more comprehensive. 'Civil Rights' and 'Right To Information' have enabled aggrieved citizens to directly prosecute polluters and hold state 
International Journal of Social Science and Economic Research

ISSN: 2455-8834

Volume: 05, Issue: 01 "January 2020"

officials more accountable (Grover, 2011). It is important to continue developments in this sphere to ensure that clean water is available to the most vulnerable and backward communities in urban India.

\section{BIBLIOGRAPHY}

Ahmed A., Khan, A., El-Rheem, A, Youssef, R.A. (2011). Influence of Sewage Water Reuse Application on Soil and the Distribution of Heavy Metal. Nature and Science, Accessed on 10th December 2019

Bhardwaj, R.M. (2005). Status of Wastewater Generation and Treatment in India. Working Group on Environment Statistics Joint Work Session on Water Statistics, Accessed on 10th December 2019

Blumenthal, U.J., Peasey, A., Ruiz-Palacios, G., Mara, D.D. (2000). Guidelines for wastewater reuse in agriculture and aquaculture: recommended revisions based on new research evidence. London School of Hygiene and Tropical Medicine. Accessed on 9th December 2019

Chow, V.T., Eliason, R., Linsley, R.K. (1972). Development and trends in wastewater Engineering. In Wastewater Engineering. McGraw-Hill Book Company. Accessed on 9th December 2019

Cooper, P.F. (2001). Historical aspects of wastewater treatment. In Decentralized sanitation and reuse concepts, systems and Implementation. IWA Publishing. London, Accessed on 9th December 2019

Dhote, J., Ingole, S.P., Chavhan, A. (2012). Review on Waste Water Treatment Technologies. International Journal of Engineering Research \& Technology, Accessed on 7th December 2019

Doorn, M.R.J., Towprayoon, S., Maria, S., Vieira, M., Irving, W., Palmer, C., Pipatti, R, Wang, C. (2006). Wastewater treatment and discharge. 2006 IPCC Guidelines for National Greenhouse Gas Inventories. Accessed on 9th December 2019

Grover, M. (2011). Degrémont Water Treatment Technologies and A Case study of 635 MLD WTP at Sonia Vihar-Delhi. Planning Commission on Working Group on Urban and Industrial Water for Twelfth Plan of Government of India, Accessed on 10th December 2019 
Kamyotra, J.S., Bhardwaj, R.M. (2011). Municipal Wastewater Management in India. Industrial Development and Finance Corporation, Accessed on 7th December 2019

Kumar, R., Singh, R.D., Sharma, K.D. (2005). Water resources of India. Current Science. Accessed on 9th December 2019

Mara, D. (2009). Design Manual for Waste Stabilization Ponds in India. University of Leeds, Accessed on 10th December 2019

Metcalf, E., Eddy, M. (2003). Wastewater Engineering: Treatment and Reuse McGraw-Hill, Accessed on 8th December

Mogasale, V.V., Ramani, E., Park, J.Y., Wierzba, T.F. (2018). Estimating Typhoid Fever Risk Associated with Lack of Access to Safe Water: A Systematic Literature Review. Journal of Environmental and Public Health, Accessed on 9th December 2019

Sugam, R.K., Jain, A., Neog, K. Rethinking wastewater management in India. The Third Pole, 15th May 2019 